Mechanisms involved in rescue of the corpus luteum during early pregnancy in lactating dairy cows

Meidan, R. The Hebrew University of Jerusalem

Wiltbank, M.C. University of Wisconsin-Madison

Project award year: 2015

Three year research project 
1. Overall Summary: This research was focused on practical application, physiology, and molecular mechanisms related to regulation of the corpus luteum (CL). Reduced fertility and pregnancy loss are critical factors in determining the reproductive efficiency and economic viability of cattle operations (reviewed in Wiltbank, Meidan et al., 2016; Wiltbank et al., 2018). Thus, our objective was to understand the mechanisms involved in regression of the CL in nonpregnant cows and maintenance of the CL during pregnancy with the intention of applying this scientific knowledge to improving fertility and reducing pregnancy losses in cattle operations. There were three Objectives. Novel findings were made on each Objective.

Objective 1: Determine whether inadequate maintenance of CL during early pregnancy (d18-32) is limiting fertility.

1) Pregnancy loss was reduced by increasing P4 in lactating dairy cows (Baez et al., 2017; acknowledged BARD but with incorrect number). Induction of an accessory CL improved fertility when the new CL was ipsilateral to the pregnancy but did not improve fertility in multiparous cows when the new CL was contralateral to the pregnancy. This novel observation drove many of the novel studies that were done at UW-Madison as part of this grant.

2) Pregnancy loss was also reduced by increasing P4 in recipients of in vitro produced embryos (Garcia-Guerra et al., unpublished; Gomez-Leon et al., unpublished). These studies were done as proposed. In addition, regression of CL was found to be the cause of pregnancy loss in over half of losses (32-60 d of pregnancy; CL regressed, pregnancy maintained with exogenous P4).

3) Based on these findings two subsequent studies were performed and published in Biology of Reproduction by UW-Madison, acknowledging BARD funding (Mezera et al., 2019; Drum et al., 2019). These studies showed the novel finding that the reason for contralateral CL regression was that the uterus of pregnancy after Day 32 secreted large pulses of prostaglandin F2 $\alpha$ (PGF).

Objective 2: Evaluate the gene expression pathways activated in the CL during early pregnancy (d18-21 after AI) and determine the hormonal pathways (systemic IFNT, changes in PGF pulse patterns, or PGE) involved in the specific transcriptomic changes.

1) Differentially expressed genes (DEGs) expression were found, using RNA-sequencing, during physiologic pulses of PGF into the uterus (Ochoa et al., 2018) or in response to natural PGF pulses during Days 18-21 of the bovine estrous cycle (Mezera et al., 2019).

2) Pregnant cows had an inhibition of PGF pulses and CL maintenance with 93 DEGs detected during early pregnancy (Mezera et al., in preparation as joint manuscript). Treatment with PGE1 (produced during early pregnancy) produced a complete inhibition of the PGF-induced changes in CL gene expression (Ochoa et al., 2018), probably due to increased uterine blood flow.

3) Studies on intrauterine interferon-tau (IFNT) were not performed due to technical problems at UW. However, studies at Wiltbank (Mezera et al., unpublished) and Meidan (Basavaraja et al., 2019) laboratories evaluated DEG in CL during early pregnancy when IFNT is present.

Objective 3: Determine the mechanisms that underlie specific transcriptomic changes and cellular pathways regulated during luteolysis or rescue of the CL using in vitro studies.

1) Treatment with IFNT in cultured luteal slices, luteal endothelial cells, or luteinized granulosa cells directly changed gene protein expression (Basavaraja et al. 2017; 2019; Barberov et al., 2019). Genes and proteins increased by IFNT were prosurvival and antiapoptotic, whereas those decreased by IFNT were luteolytic genes, such as Thrombospondin-1 or Serpin E1.

These studies provided insights into the physiologic mechanisms that regulate $\mathrm{CL}$ maintenance in early pregnancy and unexpectedly reveal novel mechanisms involved during the second month of pregnancy. The findings have major implications for the mechanisms involved in pregnancy loss and maintenance in ruminants. 


\section{Contribution of collaboration:}

The two laboratories have different approaches to understanding the objectives that were pursued in this BARD project. Therefore, results were obtained that provided novel results from various perspectives. Many of the results were obtained from research projects that were performed in the individual laboratories of the two PIs. Dr. Meidan sent a graduate student to Madison and he taught the Wiltbank laboratory the current methodology for production and treatment of luteinized granulosa cells. Some of these results were obtained with a whole-animal approach and some results were more mechanistic. Thus, as a result of the collaboration many new findings were provided and a surprising number of novel targets for fertility enhancement were discovered. The basic results will deeply influence scientific discovery in this important area of research. In addition, the practical and whole-animal discoveries are likely to have earlier application on livestock operations, particularly in decreasing pregnancy loss. Although more studies were completed than originally proposed based on the novel findings that were observed during the first two years of the project, one of the large studies with intrauterine infusion of interferon-tau that could not performed due to technical problems. Some tissues and data have been or will be shared between laboratories. This will continue to result in important publications that are either joint publications or part of future research in the laboratories of the individual PIs. Many publications have been published and others are still being prepared for publication. 


\section{Achievements:}

\section{Objective 1. Does increased P4 increase fertility in dairy cows and recipients of embryos?}

Supplementation with P4 increased fertility in heifers that were recipients of embryos (40.4 vs $53.6 \% ; \mathrm{P}<0.05)$. This effect was due to increased pregnancy loss in heifers that were not $\mathrm{P} 4$ supplemented during the period Day 27 to 34 (14.8 vs. 3.4\%) and from 27 to 60 (25.9 vs 11.9\%) of pregnancy $(\mathrm{P}<0.05 ; \mathrm{n}=210)$. A recent follow-up study was performed with a similar design ( $n=630$ heifers). In both studies, we also observed CL regression during the second half of pregnancy but maintenance of a viable pregnancy by the exogenous P4 in most heifers experiencing pregnancy loss between Day 27 and 60 of pregnancy. Thus, consistent with our original BARD hypothesis, pregnancy loss is sometimes due to inappropriate CL regression, but this was mostly observed during the second month of pregnancy (Day 27-60) and not during early pregnancy loss (Day 18 to 27). Thus, early pregnancy loss seems to be due to embryonic death and not inappropriate CL regression but, surprisingly, later pregnancy loss seems to be due to inappropriate $\mathrm{CL}$ regression in man pregnancy losses. These BARD-funded studies are being prepared for publication (Garcia-Guerra et al. and Gomez-Leon et al.).

We were not able to achieve sufficient P4 in lactating cows by supplementation with intravaginal P4 inserts (unpublished observation) and therefore we did this study by induction of an accessory CL (Baez et al., 2017). Treatment with GnRH on Day 7 of pregnancy induced an accessory CL in most lactating dairy cows, increased circulating P4 concentrations, and improved fertility $(14.8 \% ; \mathrm{n}=570$ dairy cows). However, maintenance of the accessory CL was related to whether it was on the same side as the pregnancy or the opposite side. We made the unexpected observation that most accessory CL regressed that were on the other side but CL on the same side as the pregnancy (Baez et al., 2017). This led us to propose a new model for CL regression and maintenance during bovine pregnancy (Wiltbank, Meidan et al., 2016; Baez et al., 2017). Findings from this led us to pursue novel BARD research on PGF secretion during first and second month of pregnancy (Mezera et al., 2019; Drum et al., 2019). Secretion patterns of PGF were determined in non-bred, non-pregnant cows during Days 18-21 of the estrous cycle and in pregnant animals during the same period (Mezera et al., 2019). These animals were also used for collection of CL biopsies that were analyzed by RNA-sequencing to determine the genes that were expressed during the process of natural CL regression and during pregnancy (Mezera et al., in preparation as two joint BARD publications). Clear pulses of PGF were observed in the non- 
pregnant cows. There were one or two small pulses in all cows that underwent CL regression but there was no decrease in circulating P4. There were 211 Differentially Expressed Genes (DEGs) detected after these small PGF pulses (early CL regression) that may sensitize the CL to the luteolytic pulse of PGF (> $100 \mathrm{pg} / \mathrm{ml}$ of PGF metabolite). After the luteolytic PGF pulse the CL had numerous DEGs (4,615 genes changed during later regression). Thus, this research, for the first time, described the CL gene expression pathways during natural PGF pulses.

It was also determined that PGF pulses were inhibited during early pregnancy (Day 18-25) but during the second month of pregnancy there was a dramatic increase in the number and amplitude of PGF pulses (Mezera et al., 2019). We followed up on this intriguing observation by challenging pregnant cows with oxytocin during each week from Day 10 to 60 of pregnancy. This demonstrated that early pregnancy (Days 18-25) was characterized by lack of increased PGF secretion after oxytocin challenge, most likely due to suppression of uterine oxytocin receptors by Interferon-tau (IFNT) from the embryo. However, in non-pregnant cows on Day 18 and in pregnant cows after Day 25 there was a dramatic increase in uterine PGF secretion in response to oxytocin (Drum et al., 2019). Thus, this BARD research produced the novel finding that the $\mathrm{CL}$ is maintained by different mechanisms during second month compared to first month of pregnancy. This new research area is the focus of another BARD proposal funded this year.

\section{Objective 2: What is different about the CL during pregnancy?}

As part of these studies gene expression was compared during early pregnancy to a similar time in the CL lifespan in non-pregnant cows, but prior to any PGF pulses. This allowed us to find the gene expression changes (DEGs) induced in the CL during early pregnancy. A total of 93 DEGs were detected. About a third of these genes were interferon-stimulated genes (ISGs) which was expected because interferon-tau (IFNT) is secreted in early pregnancy from the elongating embryo. Some IFNT escapes the uterus and stimulates ISG expression in the CL. Other DEGs are novel and are currently being investigated for their role in pregnancy. This joint BARDfunded research was presented at the Society for the Study of Reproduction (SSR) international meeting in 2019 and is being prepared for publication (Mezera et al.). These findings provide new targets and mechanisms for increasing fertility and reducing pregnancy loss.

Another study during this BARD project determined the changes in gene expression in response to small PGF pulses that were delivered into the uterus either alone or in the presence of another prostaglandin, PGE1. During pregnancy, IFNT from the embryo stimulates increased PGE 
production by the uterus. Therefore, we were specifically testing whether this uterine PGE would alter the gene expression response to PGF pulses of physiologic magnitude. In this study, RNAsequencing was used to obtain a complete picture of the changes in gene expression (DEGs) during PGF and PGE pulses. As expected, we found numerous DEGs ( $=955$ with FDR < 0.01 ) when we treated with physiologic pulses of PGF (Ochoa et al., 2018). Completely unexpected was the finding that PGE completely blocked all PGF-induced DEGs ( $n=0$, FDR $\leq 0.10)$. Our current hypothesis is that PGE increases uterine blood flow preventing arrival of PGF at the CL. This hypothesis will be definitively tested in the next BARD grant.

\section{Objective 3: What is the action of interferon-tau (IFNT) directly on the cells of the CL?}

This novel question was tested during in vitro experiments performed at Hebrew University. Recombinant ovine IFNT was used to treat cultured luteal slices, luteal endothelial cells (LEC), or luteinized granulosa cells (LGC). The LGC provide a purified population of cells that mimic the physiology of the highly steroidogenic large luteal cells. The luteal slices and LEC directly responded to IFNT with induction of interferon stimulated genes (ISGs), likely via the STAT1 signal transduction pathway. Most interesting, IFNT suppressed PGF-induced expression of luteolytic genes such as Thrombospondin-1 and Serpin E2 (Bagasavaraja et al. 2017). Treatment of LGC with IFNT activated ISGs but also increased cell survival proteins and inhibited proteins involved in apoptosis. Thus, novel targets for enhancing pregnancy have been discovered.

\section{Practical Implications:}

1) Local mechanisms are involved in maintaining the CL during pregnancy. Thus, pregnancies initiated on the opposite side from the CL are likely to be lost.

2) Suppression of PGF from the uterine horn with the elongating embryo seems the most important mechanism to maintain CL in early pregnancy and this could be targeted in this period. 3) Other pathways that are directly activated by IFNT in the cells of the CL were discovered and these represent novel targets for future fertility enhancement methods.

4) The local effect of the pregnancy to maintain the CL after the IFNT period was discovered. Based on the results of the PGE experiment and accessory CL regression, increased uterine blood flow protects the CL from PGF after Day 25 of pregnancy. Thus, methods to enhance uterine blood flow during this period are found to be a new target for decreasing pregnancy loss.

4) These results explain why accessory CL are less effective in increasing fertility than expected.

5) Pregnancy loss can be related to CL regression creating a novel target to increase fertility. 


\section{Changes to original Research Plan:}

The research plan was not changed but additional research was performed as part of the project, based on observations that were made during the early days of the research project. Studies in Objective 2 were not completed, due to technical problems, but alternative studies were completed.

Objective 1 was performed in three different studies. In initial studies, intravaginal P4 inserts (CIDRs) were found to not provide sufficient circulating P4 to maintain pregnancy in lactating dairy cows, as originally proposed in the BARD grant proposal. Therefore, this study was performed by inducing an accessory CL in lactating dairy cows (Baez et al., 2017). In addition, two experiments were performed, as initially proposed in lactating dairy cows using two intravaginal CIDRs but using heifers that were recipients of in vitro produced embryos, which also have high pregnancy loss (manuscripts are being prepared for publication: Garcia-Guerra et al.; Gomez-Leon et al.). In addition, studies were performed to understand the PGF pulses that were involved in the novel observation of contralateral CL regression and these studies have now been published, acknowledging BARD funding (Mezera et al., 2019; Drum et al., 2019).

Objective 2 was performed with pregnant animals, since there were technical problems with intrauterine infusion of interferon-tau. This allowed us to evaluate the gene expression in the CL during early pregnancy, compared to CL gene expression during natural luteolysis. We feel that this was a powerful method for determining some similar insights, although mechanisms could not be as clearly delineated. The results of the RNA-sequencing have been completed and the manuscripts reporting this research are being prepared for publication. The original proposal also had studies on the role of PGE in pregnancy maintenance and this study was performed in a slightly different manner but with intriguing, jointly-published results (Ochoa et al., 2018). Objective 3 was performed as proposed and studies have been published (Basavaraja et al. 2017; Basavaraja et al., 2019; Faberov et al., 2019). 


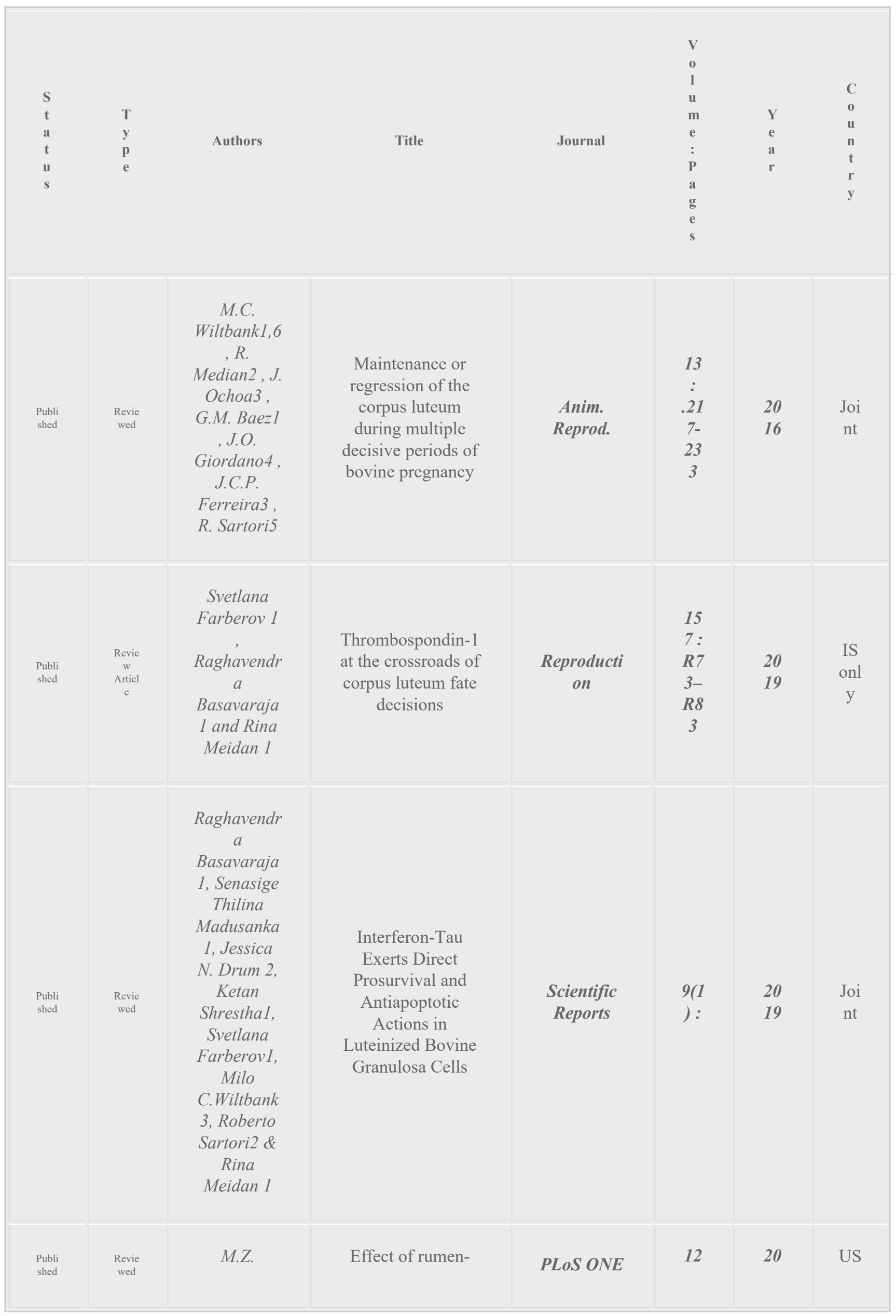


Toledo,

G.M. Baez,

A. Garcia-

Guerra,

N.E. Lobos, J.N.

protected methionine on productive and

Guenther,

E. Trevisol,

D. Luchini, reproductive performance of dairy cows.

e01

\begin{tabular}{r|c|c|}
\hline 891 & 17 & onl \\
\hline 11 & & y
\end{tabular}

Shaver,

M.C.

Wiltbank

\begin{tabular}{|c|c|c|c|c|c|c|c|}
\hline $\begin{array}{l}\text { Publi } \\
\text { shed }\end{array}$ & $\begin{array}{l}\text { Revie } \\
\text { wed }\end{array}$ & $\begin{array}{c}\text { J.C. Ochoa, } \\
\text { F. } \\
\text { Penagarica } \\
\text { n, G.M. } \\
\text { Baez, L.F. } \\
\text { Melo, J.C.L. } \\
\text { Motta, A. } \\
\text { Garcia- } \\
\text { Guerra, R. } \\
\text { Meidan, } \\
\text { J.C.P. } \\
\text { Ferreira, R. } \\
\text { Sartori, } \\
\text { M.C. } \\
\text { Wiltbank }\end{array}$ & $\begin{array}{l}\text { Mechanisms for } \\
\text { rescue of CL during } \\
\text { pregnancy: Gene } \\
\text { expression in } \\
\text { bovine CL } \\
\text { following } \\
\text { intrauterine pulses } \\
\text { of Prostaglandins } \\
\text { E1 and F2?. }\end{array}$ & $\begin{array}{c}\text { Biology of } \\
\text { Reproducti } \\
\text { on }\end{array}$ & $\begin{array}{c}98 \\
: \\
46 \\
5- \\
47 \\
9\end{array}$ & $\begin{array}{l}20 \\
18\end{array}$ & $\begin{array}{c}\text { Joi } \\
\text { nt }\end{array}$ \\
\hline $\begin{array}{l}\text { Publi } \\
\text { shed }\end{array}$ & $\begin{array}{l}\text { Revie } \\
\text { wed }\end{array}$ & $\begin{array}{c}\text { Raghavendr } \\
\text { a } \\
\text { Basavaraja } \\
\text { 1, Emilia } \\
\text { Przygrodzk } \\
\text { a2, Bartosz } \\
\text { Pawlinski3, } \\
\text { Zdzislaw } \\
\text { Gajewski3 } \\
\text { Monika M. } \\
\text { Kaczmarek2 } \\
\text {, } 3 \text { and Rina } \\
\text { Meidan1, §. }\end{array}$ & $\begin{array}{l}\text { Interferon-Tau } \\
\text { Promotes Cell } \\
\text { Survival and } \\
\text { Inhibits Specific } \\
\text { Luteolytic Genes in } \\
\text { Bovine Corpus } \\
\text { Luteum. }\end{array}$ & $\begin{array}{c}\text { Reproducti } \\
\text { on }\end{array}$ & $\begin{array}{c}15 \\
4: \\
55 \\
9- \\
56 \\
8\end{array}$ & $\begin{array}{l}20 \\
17\end{array}$ & $\begin{array}{c}\text { IS } \\
\text { onl } \\
\mathrm{y}\end{array}$ \\
\hline $\begin{array}{l}\text { Publi } \\
\text { shed }\end{array}$ & $\begin{array}{l}\text { Revie } \\
\text { wed }\end{array}$ & $\begin{array}{c}\text { Giovanni } \\
\text { M. Baez, } \\
\text { Eduardo } \\
\text { Trevisol, } \\
\text { Rafael V. } \\
\text { Barletta, } \\
\text { Beatriz O. } \\
\text { Cardoso, } \\
\text { Alessandro } \\
\text { Ricci, Jerry } \\
\text { N. } \\
\text { Guenther, } \\
\text { Nicole E. } \\
\text { Cummings, }\end{array}$ & $\begin{array}{l}\text { Proposal of a new } \\
\text { model for CL } \\
\text { regression or } \\
\text { maintenance during } \\
\text { pregnancy on the } \\
\text { basis of timing of } \\
\text { regression of } \\
\text { contralateral, } \\
\text { accessory CL in } \\
\text { pregnant cows }\end{array}$ & $\begin{array}{c}\text { Theriogeno } \\
\operatorname{logy}\end{array}$ & $\begin{array}{c}89 \\
: \\
21 \\
4- \\
22 \\
5\end{array}$ & $\begin{array}{l}20 \\
17\end{array}$ & $\begin{array}{c}\text { US } \\
\text { onl } \\
\mathrm{y}\end{array}$ \\
\hline
\end{tabular}


Milo $C$.

Wiltbank, *

J.N. Drum,

M.C.

Wiltbank,

P.L.J.

Oxytocin-induced prostaglandin

Monteiro

Jr., A.B.

$\begin{array}{ccc}\begin{array}{c}\text { Publi } \\ \text { shed }\end{array} & \begin{array}{c}\text { Revie } \\ \text { wed }\end{array} \quad \text { Prata, R.S. } \\ & & \text { Gennari, }\end{array}$

F2alpha release is

Gennari,

C.A.

low in early bovine

pregnancy but

increases during

Biology of

Reproducti

on

$: 1-\quad 20 \quad$ Joi

Gamarra,

A.M.O.

second month of

pregnancy.

Canavessi,

R. Sartori

M.A.

Mezera

Profiles of

C.S. Hamm,

C.A.

Gamarra,

R.S.

Publi Revie

Gennari,

A.B. Prata,

R. Sartori,

M.C.

Wiltbank

prostaglandin $\mathrm{F} 2 \mathrm{a}$

metabolite (PGFM)

in dairy cattle

during luteal

regression and

pregnancy:

12

19

nt

implications for

corpus luteum

maintenance.

Biology of
Reproducti

10

1 :

76-

20

US

on

90

onl

$\mathrm{y}$ 